Article

\title{
Analyzing Service Quality Evaluation Indexes of Rural Last Mile Delivery Using FCE and ISM Approach
}

\author{
Xiaohong Jiang ${ }^{1}\left(\mathbb{D}\right.$, Huiying Wang ${ }^{2}$ and Xiucheng Guo ${ }^{3, *}$ \\ 1 College of Automobile and Traffic Engineering, Nanjing Forestry University, Longpan Road 159\#, \\ Nanjing 210037, China; jiangxh@njfu.edu.cn \\ 2 Institute of Logistics Science and Engineering, Shanghai Maritime University, 1550 Haigang Ave, \\ Shanghai 201306, China; wanghuiyingholic@163.com \\ 3 School of Transportation, Southeast University, Si Pai Lou 2\#, Nanjing 210096, China \\ * Correspondence: 101002320@seu.edu.cn; Tel.: +86-1390-516-6411
}

Received: 14 May 2020; Accepted: 16 June 2020; Published: 18 June 2020

\begin{abstract}
The advent of e-commerce has led to a rapid acceleration of rural logistics development in China. To enhance green and sustainable development of rural logistics, it is necessary to improve the service quality of the rural last mile delivery and analyze service quality evaluation indexes. An integrated methodology combing fuzzy comprehensive evaluation (FCE) and the interpretative structural model (ISM) is presented in the current paper to reveal the relationship between the service quality evaluation indexes of the rural last mile delivery. A total of 18 logistics service quality evaluation indexes in five dimensions are selected. The FCE is used to measure the service quality of rural delivery in an empirical research area, and the weight of each evaluation index is assigned by regression analysis. The ISM is adopted to judge the hierarchical structure of indexes, and a five-layer hierarchy is obtained. The results show that it is necessary to first focus on improving the evaluation indexes of accuracy of goods arrival and timely customer service response. In the case of Shunfeng Express, the company needs to additionally improve the timeliness and rationality of damaged or lost processing goods. Some countermeasures and suggestions are put forward. The proposed integrated method helps to reveal the key service quality evaluation indexes and the areas needing improvement. The use of regression analysis within the FCE method allows the estimation of weights in a relatively objective way. This research provides theoretical support for improving the service quality and customers' satisfaction of the rural last mile delivery, and enhancing the green and sustainable development of rural logistics.
\end{abstract}

Keywords: rural last mile delivery; green and sustainable development; service quality; customers' satisfaction; evaluation indexes; fuzzy comprehensive evaluation; interpretative structural model

\section{Introduction}

With the continuous support of government policies, e-commerce growth in China's rural areas has led to the rapid acceleration of rural logistics development. China's rural online retail sales have steadily increased, as shown in Figure 1. From January to November 2019, China's rural online retail sales reached 1522.9 billion yuan, up 19\% year-on-year. China's online retail sales of agricultural products reached 230.5 billion yuan, up 33.8 percent year on year. In 2018, there were over 9.8 million rural e-commerce businesses in China. By May 2019, more than $99.83 \%$ of villages had a direct postal service, and $95 \%$ of towns and townships had express delivery outlets. A three-level logistics distribution system covering counties, townships, and villages has been formed. However, problems still exist, such as limited coverage of the distribution network, high logistics cost, low level of logistics 
information, slow distribution speed, and adverse impact of e-commerce logistics activities on the rural environment [1].

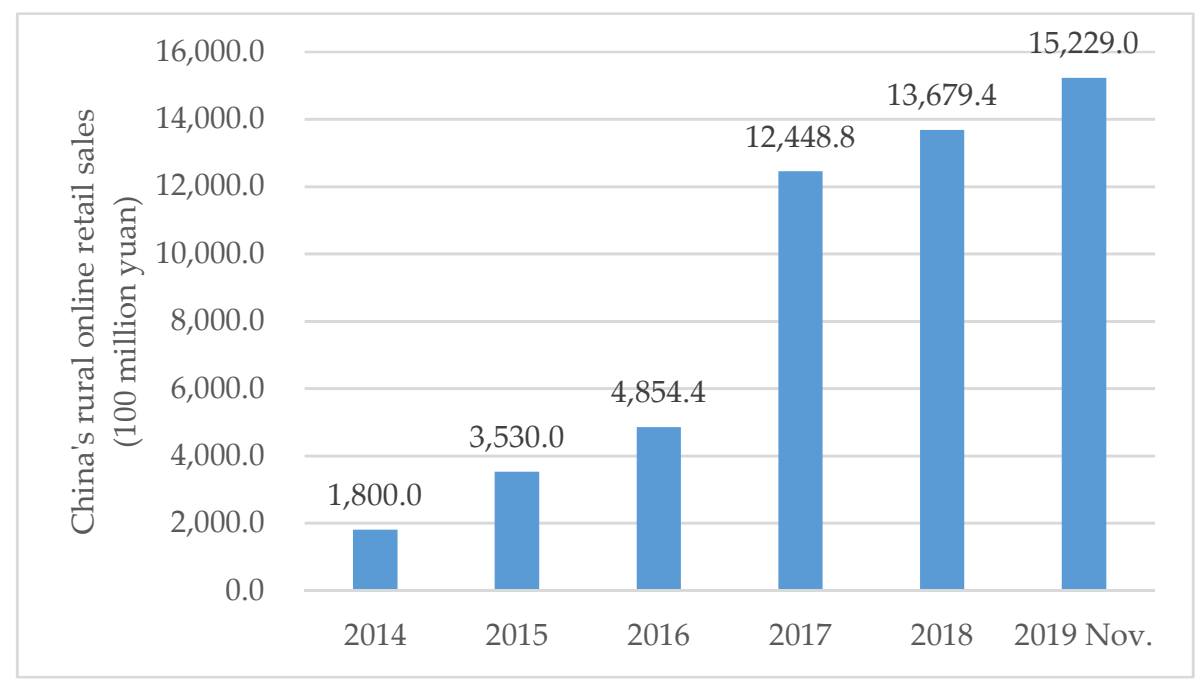

Figure 1. China's rural online retail sales from 2014 to November 2019 (Data source: China rural e-commerce market forecast and investment planning analysis report released by Chinese Qianzhan industry research institute.).

Improving the service level of the rural last mile delivery is an important means to improve the level of logistics development. The last mile delivery is the last link of delivery logistics. The service quality directly affects the shopping experience of e-commerce consumers [2] and is critical to the sustainability of a green rural logistics delivery system [3]. The rural last mile delivery features the following: (1) Dispersion: Due to the dispersion of the population in rural areas, logistics orders are relatively dispersed, which results in far higher distribution costs than those in urban areas. (2) Inconvenience: Generally speaking, it is impossible to deliver goods to a home. Almost all pick-up points are located at distribution points at the town level. Villagers are only able to collect goods themselves in the town. (3) More security risks: The rural last mile delivery generally uses an electric tricycle, making it difficult to ensure safe delivery and package quality. (4) Low efficiency: Because of the restriction of road driving conditions, distribution vehicles have a limited loading capacity and run slowly, resulting in low efficiency of distribution. These problems directly affect rural customers' experiences of receiving express deliveries and shopping, leading to a vicious development circle of e-commerce and logistics. Thus, improving the rural last mile delivery service quality is an urgent problem.

A large amount of research has been conducted into logistics service quality evaluation [4-15]. This research has mostly related to customers' satisfaction [6,7]. Through service quality evaluation, two results can be observed: (1) The scores of each service quality evaluation index and the gap between the actual and the ideal can be calculated. Logistics service issues can be identified accurately, and service quality promotion measures can be put forward. (2) The importance of each service quality evaluation index can be assigned by a weight value; however, the relationships among the evaluation indexes cannot be explored. Past research into logistics service quality was limited to the evaluation method and promotion measures [8-15]. Few studies have investigated the relationships among the evaluation indexes to propose customized promotion measures. Thus, this paper analyzes the service quality evaluation indexes of the rural last mile delivery.

The content of this paper is structured as follows. Section 2 contains a literature review. Section 3 proposes the integrated methodology. Section 4 details the empirical analysis. Section 5 contains the discussion. Conclusions are provided in Section 6. 


\section{Literature Review}

A large amount of research has been carried out into logistics service quality evaluation [4-15]. Parasuranman, Zeitham, and Berry first proposed the concept of logistics service quality [4]. The original conceptualization of service quality by Parasuraman et al. (1985) included sensitivity, courtesy, and customer knowledge [4]. The subsequent SERVQUAL included sensitivity and empathy dimensions [5]. Courtesy was relocated into the trust dimension of SERVQUAL. The other elements of this trust dimension were more closely linked to privacy and security, which has been shown to be a different dimension in the virtual context [6]. The SERVQUAL model was proposed by Mentzer, in which service quality was analyzed according to five dimensions, namely, responsiveness, reliability, caring, tangibility, and accuracy [7]. Research to date into logistics services quality evaluation has mostly been conducted from the perspective of customers' satisfaction [8-12]. Eduard developed a multiple-item scale for measuring e-service quality-web design, customer service, assurance, and order management-in which perceived quality influences satisfaction, and satisfaction influences consumer loyalty [10]. Norizan investigated the relationship between perceived service quality, satisfaction, trust, and loyalty in e-commerce settings [11]. Saura found that consumers had positive perceptions of such topics as exclusive promotions and smartphones; by contrast, topics such as fraud, insults and noise, and customer support were negatively perceived by customers [12].

Service quality evaluation methods include the analytic hierarchy process (AHP) [13,14], gap analysis [15,16], technique for order preference by similarity to an ideal solution (TOPSIS) [17], fuzzy comprehensive evaluation (FCE) [18-20], and the gray evaluation method.

Through previous service quality evaluations, two results can be observed: (1) The scores of each service quality evaluation index and the gap between the actual and the ideal can be calculated. The logistics service issues can be identified accurately, and service quality promotion measures can be put forward. (2) The importance of each service quality evaluation index can be assigned by a weight value, but the relationships among the evaluation indexes cannot be explored. Past research into the logistics service quality were limited to the evaluation method and promotion measures [13-20]. There are few studies into the relationships among the evaluation indexes to propose customized promotion measures.

A common method of analyzing the relationships among influencing factors is the interpretative structural model (ISM), which was proposed by Warfield in 1974 [21]. The ISM has been applied in various areas, such as identifying the factors influencing e-diplomacy implementation, safety management, and potential systemic accidents [22-26]. Applications of the ISM to analysis of the supply chain and logistics are few. Jiang studied the sustainability influencing factors of the last mile delivery [27]. However, subjectivity is a shortcoming of the ISM, as judgement of the key factors depends on experience. Thus, the integrated method of the ISM and AHP or TOPSIS was proposed to analyze the influencing factors [28-33]. However, the existing research has shortcomings: the weights in AHP are subjective and, while TOPSIS is suitable for evaluating the target decisions of several alternatives, obtaining the feature vector is difficult and expert scoring is subjective, which directly reduces evaluation accuracy and efficiency. Therefore, FCE has been applied to assign weights to evaluation indexes, with regression analysis adopted to assign the weight vector of the evaluation indexes. The advantage of FCE is that it is carried out step-by-step from a low level to a high level. The modeling process is simple and easy to master. For multi-layer, multi-index complex objects, in particular, its evaluation results are more accurate. Furthermore, regression analysis is a relatively objective valuation method.

To fill the existing research gaps, the current paper analyses the service quality evaluation indexes of the rural last mile delivery based on a method that integrates the FCE and ISM. The FCE is used to assign the weight and degree of evaluation indexes, so the evaluation is conducted with objectivity and emphasis. The ISM is applied to explore the relationships among the typical evaluation indexes, and reveal their order of importance. An empirical analysis is carried out, and service quality promotion measures are put forward. 


\section{Research Methodology}

A method that integrates FCE and ISM was applied to this research. Firstly, the evaluation indexes of rural delivery service quality were selected. Secondly, taking a questionnaire of last mile delivery service quality in a rural area as an example, the FCE was adopted to calculate the evaluation result of this example, and the indexes to be improved were identified. Regression analysis was used to assign the indexes' weights. Thirdly, ISM was applied to clarify the inter-relationship between the evaluation indexes. Finally, the FCE results of the example service quality and the ISM analysis results were comprehensively analyzed, and promotion measures for improving the rural delivery development in the example area are then proposed.

\subsection{Service Quality Evaluation Indexes Selecting}

The selection of service quality evaluation indexes is an important process of this study. Expert interviews and literature review were adopted to collect the evaluation indexes. A literature review was conducted on the logistics service quality evaluation. The original conceptualization of service quality by Parasuraman et al. (1985) included the following dimensions: courtesy, sensitivity, and customer knowledge [4]. The subsequent SERVQUAL dimension included sensitivity (willingness to help customers) and empathy (individual attention) [5]. Courtesy was relocated into the trust dimension of SERVQUAL. The other elements of this trust dimension were more closely linked to privacy and security, which has been shown to be a different dimension in the virtual context [6]. Service quality is related to service reliability, customer sensitivity, a personalized service, and a fast response to complaints. The class SERVQUAL model was proposed by Mentzer, and the service quality was analyzed according to five dimensions, namely, responsiveness, reliability, caring, tangibility, and accuracy [7]. In the current study, modifications were made to the class SEVQUAL model according to the service demand of rural delivery, as follows:

- Change "Tangibility" to "Convenience"

Tangibility mainly applies to offline physical shopping. Regarding the currently popular online shopping, it is no longer applicable. Consumers are more inclined to the convenience of online shopping. Therefore, in this study, "convenience" can replace "tangibility". Online shopping provides convenient payment methods, logistics information queries, door-to-door delivery, and other services. The rationality of the distribution layout also reflects the convenience of service. Considering the rural consumers' backward consumption concept, the evaluation index "convenience of payment" is increased.

- $\quad$ Add "Reactivity"

In contrast to service responsiveness, service reactivity focuses on the reactions of enterprises in dealing with damaged or lost goods and other special situations. Therefore, service reactivity is added.

- Retain "Accuracy"

Assurance means that the professional quality, professional skills, and service level of employees are reliable. The assurance of logistics service means the accuracy of logistics information and goods arrival, and a strict standard of contract processing. As a result, accuracy is maintained.

- Retain "Caring"

In logistics service, caring refers to the employees' service attitude, work ability, and external dress in front of customers. As a result, caring is maintained. Considering the scattered residence of rural consumers, the evaluation index "timely notification after goods arrival" is added.

- Retain "Responsiveness" 
Customers expect logistics companies and e-commerce to deal with some issues quickly, such as timely response to goods delivery, pick-up, and customers' questions, etc.

In addition, these evaluation indexes were reviewed and recognized to be reasonable by four experts from a university and an express company. The 18 evaluation indexes in five dimensions, namely, service convenience, reactivity, accuracy, caring, and responsiveness, are shown in Table 1. The third column shows the authors who previously used these criteria.

Table 1. Service quality evaluation indexes of the rural last mile delivery.

\begin{tabular}{|c|c|c|}
\hline Dimension & Evaluation Indexes & Adapted From \\
\hline Service convenience (B1) & $\begin{array}{c}\text { Rationality of distribution layout }\left(S_{01}\right) \\
\text { Convenience of payment }\left(S_{02}\right) \\
\text { Convenience of Information query }\left(S_{03}\right) \\
\text { Convenience of the delivery time setting }\left(S_{04}\right) \\
\text { Convenience of the delivery }\left(S_{05}\right)\end{array}$ & $\begin{array}{l}\text { Yang (2004) [34], Zeithaml (2001) [35], Cox and } \\
\text { Dale (2001) [36], Liu and Arnett (2000) [37], van } \\
\text { Riel (2004) [38], Barnes and Vidgen (2002) [39] }\end{array}$ \\
\hline Service reactivity (B2) & $\begin{array}{l}\text { Timely customer service response }\left(S_{06}\right) \\
\text { Rationality of damaged or lost goods process }\left(S_{07}\right) \\
\text { Timely processing of damaged or lost goods }\left(S_{08}\right)\end{array}$ & $\begin{array}{l}\text { Loiacono (2000) [40], Yoo and Donthu (2001) [41], } \\
\text { Madu (2002) [42], Zeithaml (2001) [43] }\end{array}$ \\
\hline Service accuracy (B3) & $\begin{array}{l}\text { Accuracy of goods arrival }\left(S_{09}\right) \\
\text { Accuracy of logistics information }\left(S_{10}\right) \\
\text { Strict regulation of the signing processing }\left(S_{11}\right)\end{array}$ & $\begin{array}{c}\text { Madu (2002) [42], Liu and Arnett (2000) [37], van } \\
\text { Riel (2004) [38], Barnes and Vidgen (2002) [39], } \\
\text { Yang (2004) [34] }\end{array}$ \\
\hline Service caring (B4) & $\begin{array}{c}\text { Notification after goods arrival timely }\left(S_{12}\right) \\
\text { Employees remind customers to open the packages } \\
\text { actively }\left(S_{13}\right) \\
\text { Employees' service attitude }\left(S_{14}\right) \\
\text { Employees ask what other needs actively }\left(S_{15}\right)\end{array}$ & $\begin{array}{l}\text { Liu and Arnett (2000) [37], van Riel (2004) [38], } \\
\text { Barnes and Vidgen (2002) [39], Yang (2004) [34] }\end{array}$ \\
\hline
\end{tabular}

\subsection{Service Quality Questionnaire Based on Customer Satisfaction}

A service quality questionnaire based on customer satisfaction was required to collect the necessary data. The logistics companies in rural areas of Hai'an County, Nantong City, Jiangsu Province were taken as an example for empirical analysis. The logistics companies mainly included Suning, Jingdong, Shunfeng, Sitong, and Post. In the rural last mile delivery, it is impossible to deliver goods to home. Almost all of the pick-up points are located at distribution points at the town level; thus, villagers can only pick up goods themselves in the town. The service quality questionnaire based on customer satisfaction was conducted on the town distribution points of these five companies.

This questionnaire consisted of two parts. One part concerned the customers' basic information, including age, gender, occupation and income. The other part was the main body of this questionnaire, and mainly asked customers to score the service quality of the last mile delivery of the above five logistics companies. The scores were five grades from 1 to 5 . The questions covered the five dimensions and 18 service quality evaluation indexes mentioned above.

The questionnaire was completed as a paper or online questionnaire. The paper questionnaires were completed in Qutang Town, Hai'an County, Nantong City, and were mainly distributed to customers who came to various delivery points to pick up their packages. The online questionnaire used network tools, such as Questionnaire Star, WeChat, and QQ. The survey period lasted 6 days and 100 questionnaires were issued for each company. A total of 487 valid questionnaires were collected.

\subsection{Fuzzy Comprehensive Evaluation}

The FCE is a comprehensive evaluation method based on fuzzy mathematics. According to the membership degree theory of fuzzy mathematics, this method transforms qualitative evaluation into quantitative evaluation, that is, using fuzzy mathematics to make an overall evaluation of things or objects subject to various factors. This method can yield a strong system and obtain clear results, and can solve fuzzy and difficult to quantify problems [43]. It is highly suitable for addressing non-deterministic issues. The following are the detailed steps: 
St. 1 : Determine the set of evaluation indexes as the fuzzy subset, $p, p=\left\{p_{1}, p_{2}, \ldots, p_{m}\right\}$, where $m$ is the number of indexes, $i=1,2, \ldots, m$. Take the service quality evaluation indexes proposed in Section 3.1 as the evaluation index set.

St. 2: Establish a suitable fuzzy membership function to build an evaluation matrix for evaluation indexes, $R, R=\left(r_{i j}\right)_{m \times n}$. Since the service quality grading standards are fuzzy, it is reasonable to characterize the gradational boundary. Let $r_{i j}$ be the fuzzy membership degree of the $i$ th evaluation index to the $j$ th evaluation index grade. Then, their relationship represents the membership function, thus comprising the fuzzy relationship matrix $R$ of service quality evaluation indexes and quality levels. $n$ is the grade of service quality, $j=1,2, \ldots, n$.

The membership function determines the fuzziness in a fuzzy set. The process of membership value assignment can be done through rank ordering, inference, angular fuzzy sets, intuition, genetic algorithms, inductive reasoning and neural networks. The membership functions include trapezoidal, triangular, generalized bell, sigmoidal and Gaussian. The only condition for a membership function to be satisfied is that it must vary between 0 and 1 [23]. The triangular membership function is a particular case of trapezoidal functions, and can comply with relevant optimization criteria. Furthermore, it consists of simple straight-line segments and simple formulas, and is thus used extensively. The triangular membership function is adopted here.

St. 3: Use regression analysis to assign the weight of the evaluation indexes, $W$, $W=\left(w_{1}, w_{2}, \ldots, w_{m}\right)$. The data for the regression analysis are derived from the service quality questionnaire mentioned in Section 3.2.

St. 4: Calculate the fuzzy comprehensive evaluation result using a suitable fuzzy synthesis operator. In this study, the weighted average fuzzy synthesis operator was adopted to derive the fuzzy evaluation result, that is, the product of the weight vector and the evaluation matrix, $B$, as shown in the following formula:

$$
B=\left(b_{1}, b_{2}, b_{3}, \ldots, b_{n}\right)=W \times R=\left(w_{1}, w_{2}, \ldots, w_{m}\right) \times\left[\begin{array}{ccccc}
r_{11}, & r_{12}, & r_{13}, & \ldots, & r_{1 n} \\
r_{21}, & r_{22}, & r_{23}, & \ldots, & r_{2 n} \\
\vdots & \vdots & \vdots & \ddots & \vdots \\
r_{m 1}, & r_{m 2}, & r_{m 3}, & \ldots, & r_{m n}
\end{array}\right]
$$

Here, the set of evaluation indexes is the fuzzy set \{very bad, bad, medium, good, very good\}. The set is recorded $B=\{1,2,3,4,5\}$, by the $1-5$ measurement method.

\subsection{Interpretative Structural Model}

The ISM is suitable for a system analysis with many variables, unclear structure, and complex relationships [2]. The fuzzy views and ideas can be transformed into intuitive models with good structural relationships based on this model. The following are the specific steps:

St. 1: The set of evaluation indexes proposed in Section 3.1 are denoted $S=\left\{S_{1}, S_{2}, S_{3}, \ldots \ldots S_{m}\right\}$, and the indexes are denoted $S_{m}, m=1,2,3, \ldots$.

St. 2: Quantify the evaluation indexes strength and judge the key evaluation index. According to the evaluation index weights assigned by the FCE, the AEIOU method is applied to classify the indexes and judge the key index. A, E, I, O, and U represent very important, especially important, important, ordinary, and unimportant, respectively, and account for $10 \%, 20 \%, 30 \%, 40 \%$, and 0 , respectively.

St. 3: Build the adjacency Boolean matrix, $A$, according to the direct binary relationships among the evaluation indexes. Based on the indexes and situation, a contextual relationship is chosen from the options: "depend on", "lead to", "impact", "increase", and "decrease". A direct binary relationship, $a_{i j}$, is used to estimate the relationship between any two indexes.

(1) If $i$ has no impact on $j, a_{i j}=0$; else, $a_{i j}=1$, and vice versa;

(2) If the two indexes impact each other, then $a_{i j}=a_{j i}=1$;

(3) If the two indexes do not impact each other, then $a_{i j}=a_{j i}=0$; 
(4) When $i=j$, then $a_{i j}=a_{j i}=0$;

(5) $\quad a_{i j}=a_{j i}=0$ for any key indexes.

St. 4: Build the reachability matrix, $R$. Based on the transition law characteristics, $R$ is generated by the Boolean algebra algorithm-based process as follows:

$$
(A+I) \neq(A+I)^{2} \neq \ldots \neq(A+I)^{k}=(A+I)^{k+1}=R
$$

where $I$ is the unit matrix, and $k$ is defined as less than or equal to the number of indexes. $(A+I)$ is multiplied by itself based on the algorithm until a power of the product reaches the identity matrix.

St. 5: Divide $R$ into different layers. The antecedent sets and reachability sets of every index should be obtained based on $R$. The antecedent sets consist of the index itself and other indexes that may affect it, and the reachability sets consist of the index itself and the other indexes it may affect. There is a strong relationship if $R\left(S_{i}\right) \cap A\left(S_{i}\right)=R\left(S_{i}\right)$, and the index in $R$ will be removed from consideration and located in the top layer. The above steps should be repeated to obtain all layers of indexes.

St. 6: Draw a multilayer ladder directed graph. According to the results of St. 5, the top-layer indexes are placed at the hierarchy top, and the second-layer indexes are placed below the top layer. This step should be repeated until the underlying indexes are placed at the lowest position.

\subsection{The Integrated Methodology}

This research was generally carried out in three major steps. First, the service quality evaluation indexes were selected. Taking the service quality questionnaire of the last mile delivery in a rural area as an example, the FCE was used to obtain the service quality evaluation result of this example. The weight of each evaluation index was assigned by the regression analysis method, and the evaluation indexes to be improved were identified. Second, the ISM was applied to clarify the hierarchical layer of the mutual relationships among the evaluation indexes. The weight results assigned by the FCE were applied to analyze the intensity of the evaluation indexes. The interrelationships among the evaluation indexes were clarified and the key indexes were identified. Third, based on results of the FCE and ISM, the measures for improving the last mile delivery service quality were proposed. Figure 2 shows the flowchart of this integrated method.

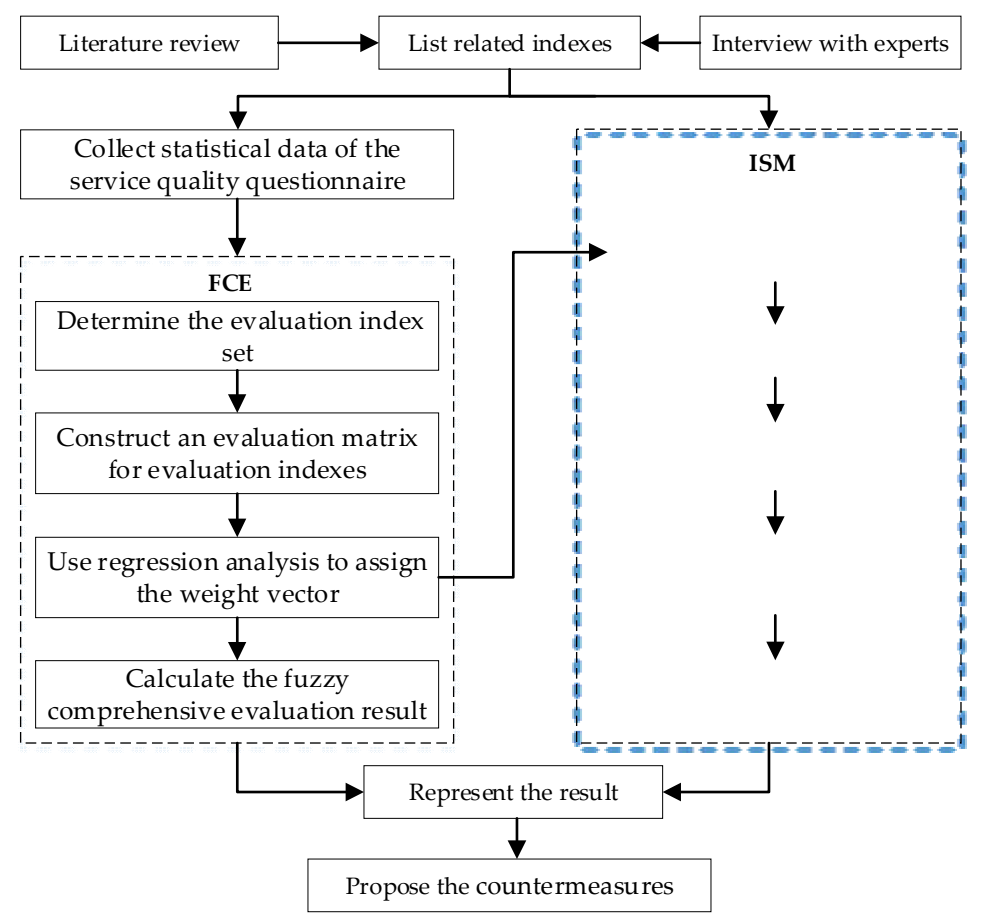

Figure 2. Flowchart of the integrated methodology. 


\section{Empirical Analysis}

\subsection{FCE Result}

The data were collected from questionnaires distributed in Hai'an County, Nantong City. The weight and rank of the five dimensions and 18 service quality evaluation indexes were assigned using regression analysis. Firstly, the regression coefficients of each dimension were obtained, as shown in Table 2.

Table 2. Regression analysis of five dimensions.

\begin{tabular}{ccccc}
\hline \multirow{2}{*}{ Independent Variable } & \multicolumn{2}{c}{ Unstandardized Coefficients } & $\begin{array}{c}\text { Standardized } \\
\text { Coefficients }\end{array}$ & $\begin{array}{c}\text { Confidence } \\
\text { Coefficient }\end{array}$ \\
\cline { 2 - 4 } & Regression Coefficient & Standard Error & Regression Coefficient & 2.339 \\
Service convenience & 0.262 & 0.021 & 0.283 & 0.028 \\
Service reactivity & 0.144 & 0.012 & 0.156 & 0.067 \\
Service accuracy & 0.167 & 0.013 & 0.181 & 0.739 \\
Service caring & 0.195 & 0.016 & 0.211 & 1.138 \\
Service responsiveness & 0.156 & 0.013 & 0.169 & 0.266 \\
\hline
\end{tabular}

The regression coefficients were normalized as follows, and the results were taken as the weight vector of the evaluation indicator dimension. Similarly, the weight and ranking of the 18 evaluation indexes of the last mile delivery service quality were calculated as shown in Table 3 and Figure 3. The rank of dimension weights from high to low is service convenience (B1), caring (B4), accuracy (B3), responsiveness (B5), and reactivity (B2). The dimensions of the evaluation indexes in the horizontal coordinates of Figure 3 are ranked according to their weight values, from highest to lowest. The last two columns of Table 3 show the weight and rank of the 18 evaluation indexes. The five most important indexes are $S_{09}, S_{03}, S_{10}, S_{12}$, and $S_{04}$.

Table 3. The results of weight and rank of the evaluation indexes.

\begin{tabular}{cccccccc}
\hline \multirow{2}{*}{ Indexes } & $\mathbf{B 1}$ & $\mathbf{B 2}$ & $\mathbf{B 3}$ & $\mathbf{B 4}$ & $\mathbf{B 5}$ & \multirow{2}{*}{ Proportion } & Rank \\
\cline { 2 - 6 } & $\mathbf{0 . 2 8 3}$ & $\mathbf{0 . 1 5 6}$ & $\mathbf{0 . 1 8 1}$ & $\mathbf{0 . 2 1 1}$ & $\mathbf{0 . 1 6 9}$ & & \\
\hline$S_{01}$ & 0.173 & 0 & 0 & 0 & 0 & 0.048959 & 18 \\
$S_{02}$ & 0.198 & 0 & 0 & 0 & 0 & 0.056034 & 8 \\
$S_{03}$ & 0.225 & 0 & 0 & 0 & 0 & 0.063675 & 2 \\
$S_{04}$ & 0.210 & 0 & 0 & 0 & 0 & 0.059430 & 5 \\
$S_{05}$ & 0.188 & 0 & 0 & 0 & 0 & 0.053770 & 11 \\
$S_{06}$ & 0 & 0.351 & 0 & 0 & 0 & 0.054756 & 9 \\
$S_{07}$ & 0 & 0.324 & 0 & 0 & 0 & 0.050544 & 15 \\
$S_{08}$ & 0 & 0.325 & 0 & 0 & 0 & 0.050700 & 14 \\
$S_{09}$ & 0 & 0 & 0.354 & 0 & 0 & 0.064074 & 1 \\
$S_{10}$ & 0 & 0 & 0.344 & 0 & 0 & 0.062264 & 3 \\
$S_{11}$ & 0 & 0 & 0.302 & 0 & 0 & 0.054662 & 10 \\
$S_{12}$ & 0 & 0 & 0 & 0.276 & 0 & 0.060840 & 4 \\
$S_{13}$ & 0 & 0 & 0 & 0.251 & 0 & 0.052961 & 12 \\
$S_{14}$ & 0 & 0 & 0 & 0.239 & 0 & 0.050429 & 16 \\
$S_{15}$ & 0 & 0 & 0 & 0.234 & 0 & 0.049374 & 17 \\
$S_{16}$ & 0 & 0 & 0 & 0 & 0.334 & 0.056446 & 7 \\
$S_{17}$ & 0 & 0 & 0 & 0 & 0.306 & 0.051714 & 13 \\
$S_{18}$ & 0 & 0 & 0 & 0 & 0.360 & 0.058236 & 6 \\
\hline
\end{tabular}




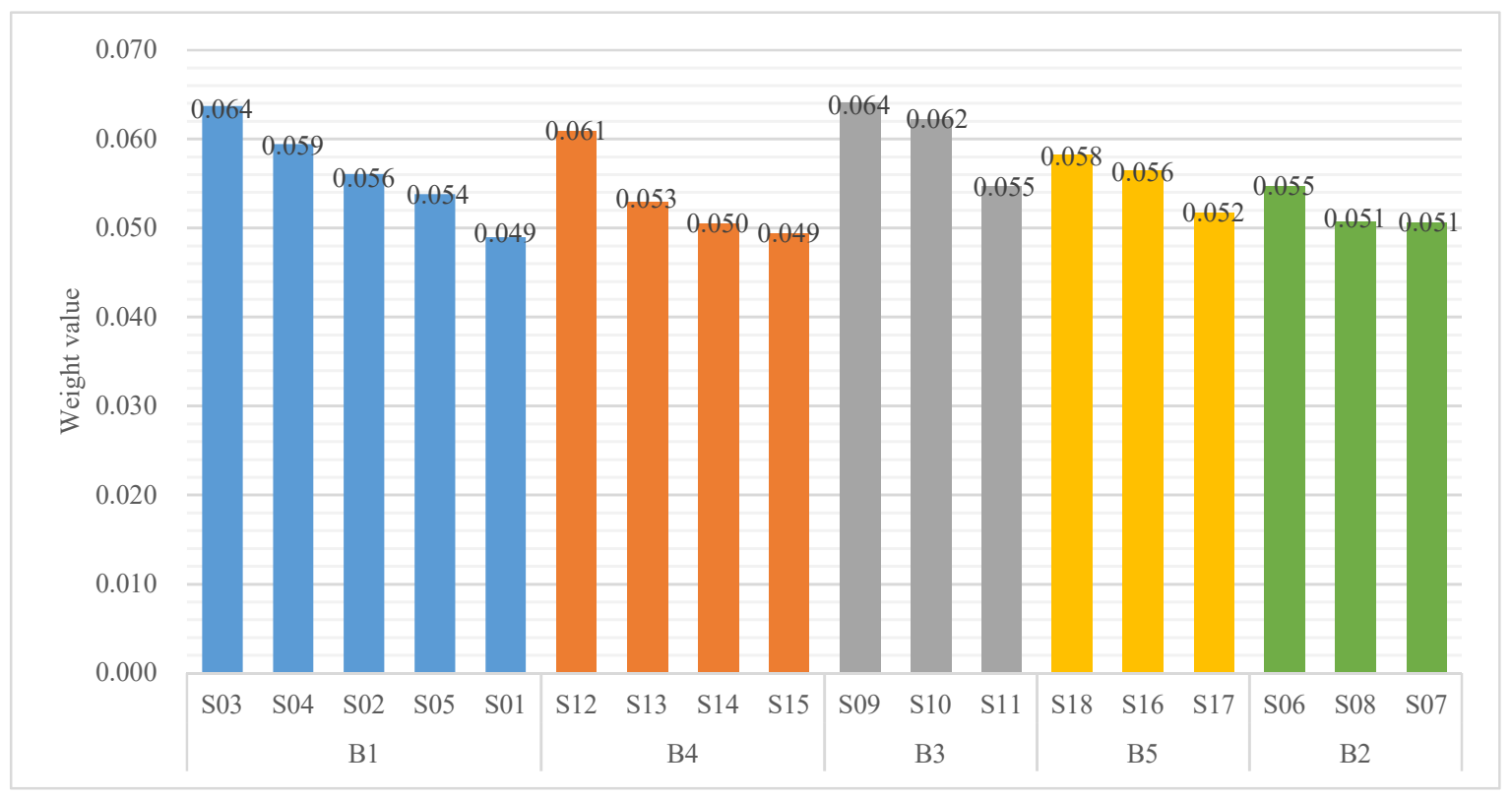

Figure 3. The weight value of the 18 evaluation indexes.

The FCE was used to conduct the evaluation analysis of each logistics company, and Figure 4 shows the results. The total score is 5 , indicating that the customer satisfaction of all companies is medium. The comprehensive evaluation score from high to low is Post, Sitong, Shunfeng, Suning, and Jingdong.

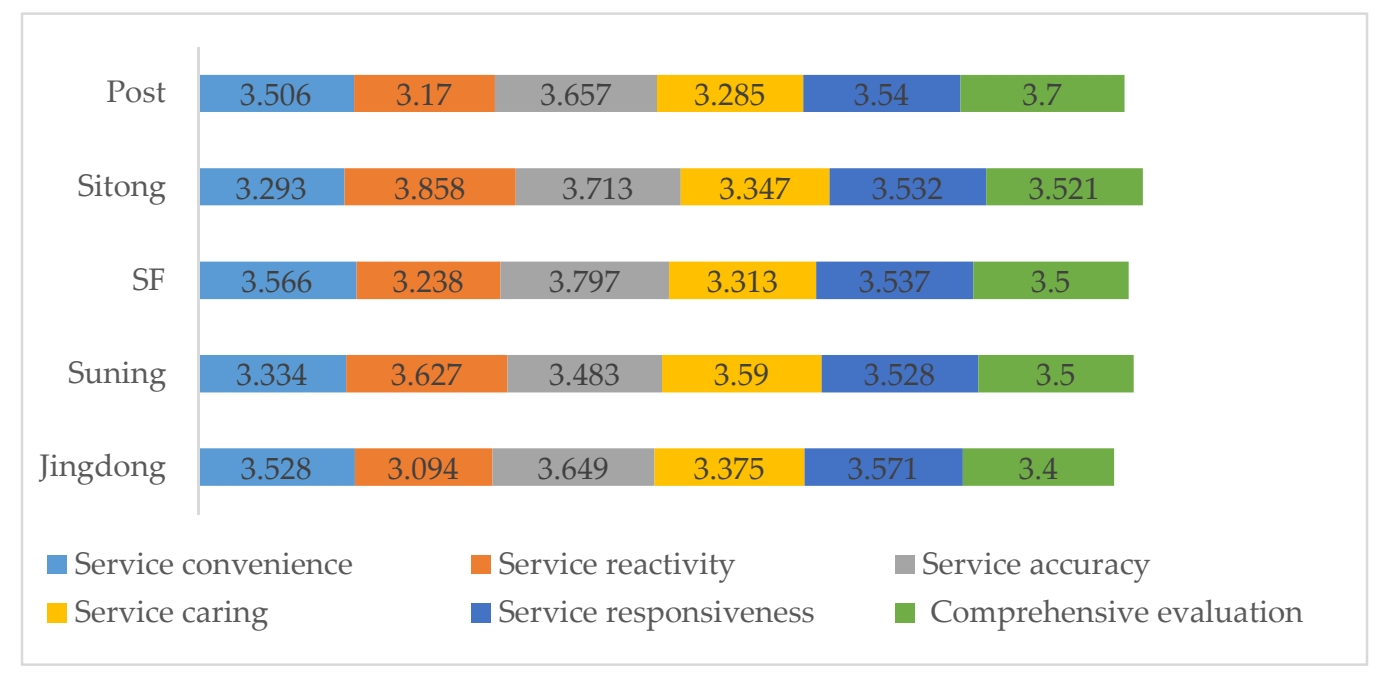

Figure 4. Service quality evaluation results of five logistics companies.

\subsection{ISM Result}

This section presents the results of the ISM described in Section 3.4. The indexes were classified by using AEIOU and regression analysis. $S_{09}$ and $S_{03}$ are very important indexes. $S_{10}, S_{12}$ and $S_{04}$ are especially important indexes. $S_{18}, S_{16}, S_{02}, S_{06}$ and $S_{11}$ are important indexes. $S_{05}, S_{13}, S_{17}, S_{08}, S_{07}$, $S_{14}$ and $S_{15}$ are ordinary indexes. $S_{01}$ is unimportant index. When establishing $R, S_{03}, S_{04}, S_{09}, S_{10}$ and $S_{12}$ were considered as source points, which represent the fundamental indexes affecting the service quality of terminal distribution. As seen from Figure 5, all of the elements in line 19 of the adjacency matrix, $A$, are set to $0 . S_{19}$ is the sink point. 


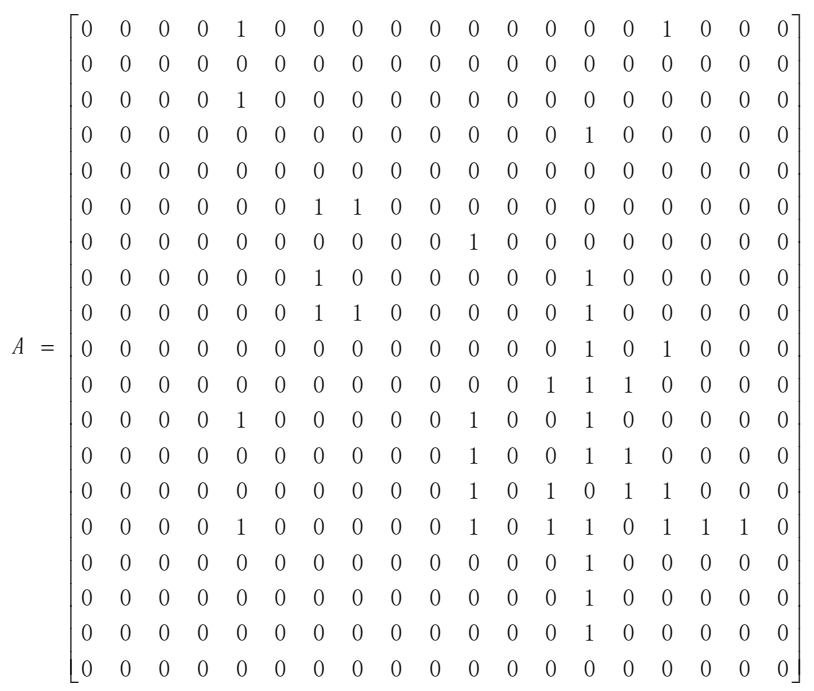

Figure 5. Adjacency matrix.

Based on the transition law characteristics, the reachability matrix, $R$, was built as shown in Figure 6.

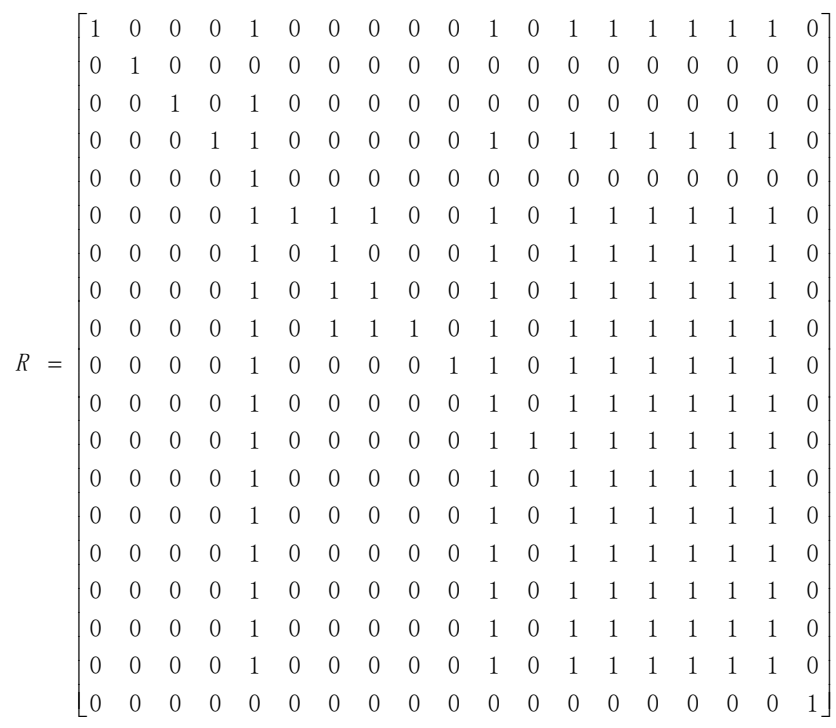

Figure 6. Reachability matrix.

Table 4 shows the layer 1 partitioning of $R$. The indexes of $A\left(S_{i}\right)$ in the third column consist of the indexes that are represented as a 1 in each column of the matrix $R$. The indexes of $R\left(S_{i}\right)$ in the second column consist of the indexes that are represented as a 1 in each row. The indexes of $R\left(S_{i}\right) \cap A\left(S_{i}\right)$ are shown in the last column, which are the elements that should be placed in the first layer. The indexes of $R\left(S_{i}\right) \cap A\left(S_{i}\right)=A\left(S_{i}\right)$ are $S_{01}, S_{02}, S_{03}, S_{04}, S_{06}, S_{09}, S_{10}, S_{12}$. The indexes of $R\left(S_{i}\right) \cap A\left(S_{i}\right)=R\left(S_{i}\right)$ are $S_{02}, S_{05}$. Indexes with strong connections $\left(S_{02}, S_{05}, S_{19}\right)$ are deleted, then indexes of layer 1 are $S_{02}, S_{05}$, $S_{19}$. After repeating the above steps, it can be found that the layer 2 indexes are $S_{03}, S_{11}, S_{13}, S_{14}, S_{15}$ $S_{16}, S_{17}, S_{18}$. The layer 3 indexes are $S_{01}, S_{04}, S_{07}, S_{10}, S_{12}$. The layer 4 indexes are $S_{08}$, and the layer 5 indexes are $S_{06}, S_{09}$. 
Table 4. Layer 1 partition of $R$.

\begin{tabular}{cccc}
\hline Indexes & $\boldsymbol{R}\left(S_{\boldsymbol{i}}\right)$ & $A\left(S_{i}\right)$ & $\boldsymbol{R}\left(S_{\boldsymbol{i}}\right) \cap A\left(S_{\boldsymbol{i}}\right)$ \\
\hline$S_{01}$ & $1,5,11,13-18$ & 1 & 1 \\
$S_{02}$ & 2 & 2 & 2 \\
$S_{03}$ & 3,5 & 3 & 3 \\
$S_{04}$ & $4,5,11,13-18$ & 4 & 4 \\
$S_{05}$ & 5 & $1,3,4-18$ & 5 \\
$S_{06}$ & $5,6,7,8,11,13-18$ & 6 & 6 \\
$S_{07}$ & $5,7,11,13-18$ & $6,7,8,9$ & 7 \\
$S_{08}$ & $5,7,8,11,13-18$ & $6,8,9$ & 8 \\
$S_{09}$ & $5,7,8,9,11$ & 9 & 9 \\
$S_{10}$ & $5,10,11,13-18$ & 10 & 10 \\
$S_{11}$ & $5,11,13-18$ & $1,4,6-18$ & $13-18$ \\
$S_{12}$ & $5,11,12,13-18$ & 12 & 12 \\
$S_{13}$ & $5,11,13-18$ & $1,4,6-18$ & $11,13-18$ \\
$S_{14}$ & $5,11,13-18$ & $1,4,6-18$ & $11,13-18$ \\
$S_{15}$ & $5,11,13-18$ & $1,4,6-18$ & $11,13-18$ \\
$S_{16}$ & $5,11,13-18$ & $1,4,6-18$ & $11,13-18$ \\
$S_{17}$ & $5,11,13-18$ & $1,4,6-18$ & $11,13-18$ \\
$S_{18}$ & $5,11,13-18$ & $1,4,6-18$ & $11,13-18$ \\
\hline
\end{tabular}

Based on the layer partition results, the interpretative structure model for the last mile delivery service quality is achieved, which is a five-layer hierarchy as presented in Figure 7.

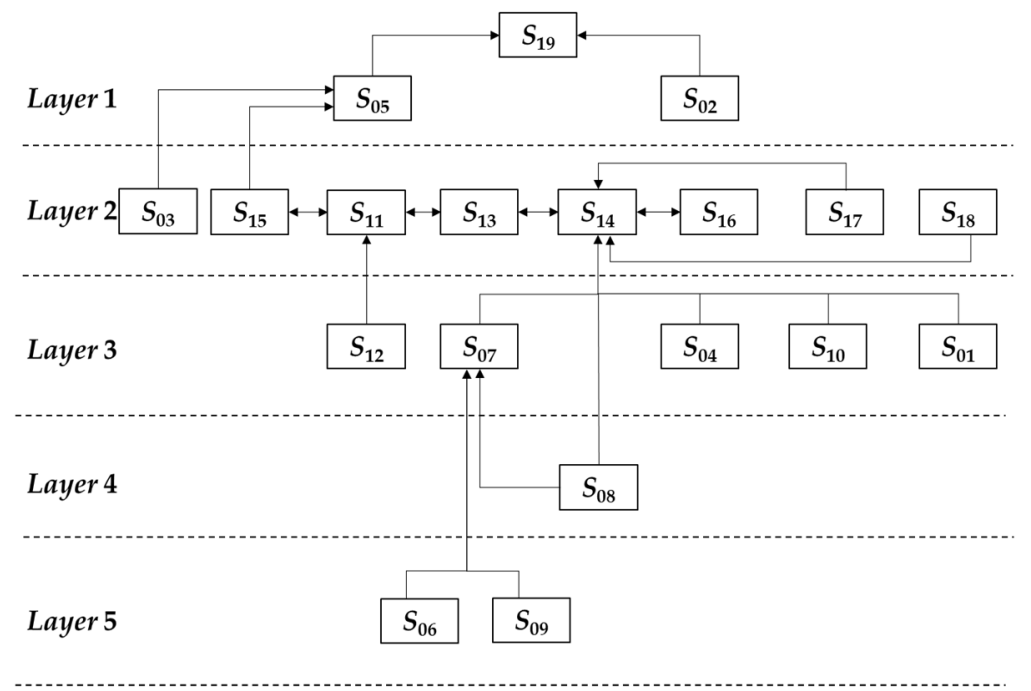

Figure 7. Interpretative structural model.

\section{Discussion}

Based on this integrated methodology of the FCE and ISM, this section provides a comprehensive discussion about each index. The importance weights of the indexes are assigned and the influence paths of each index are expounded clearly.

These weights indicate the importance of the evaluation indexes. As seen from Table 2, the rank of dimension weights from high to low is service convenience (B1), caring (B4), accuracy (B3), responsiveness (B5), and reactivity (B2). The five most important indexes are "accuracy of goods arrival $\left(S_{09}\right)$ ", "convenience of Information query $\left(S_{03}\right)$ ", "accuracy of logistics information $\left(S_{10}\right)$ ", "timely notification after goods arrival $\left(S_{12}\right)$ ", and "convenience of setting the delivery time $\left(S_{04}\right)$ ". The work links corresponding to these five indexes are considered from the perspective of logistics companies. If the companies perform well in these five work links, customers will feel more comfortable 
with the delivery services. Therefore, companies need to gradually perfect their training systems for staff.

Taking Shunfeng Express as an example, it could be seen that the evaluation results of the five dimensions from low to high are service responsiveness, service caring, service economy, service convenience, and service reliability. These evaluation results indicate that there is a need to focus on improvement in order to improve overall service layers.

The ISM model explains the relationships among all of the evaluation indexes, which are classified into five layers. The indexes at the bottom layer are "timely customer service response $\left(S_{06}\right)$ " and "accuracy of goods arrival $\left(S_{09}\right)$ ". These two evaluation indexes are the most basic indexes to improve service quality, and are also the deepest and non-negligible indexes. Timely customer service response and accuracy of goods arrival are the factors that most directly affect consumer satisfaction and contribute to lower levels of consumer satisfaction. These two evaluation indexes must be addressed first. The indexes located in the middle layer, namely the third and fourth layer, are "timely processing of damaged or lost goods $\left(S_{08}\right)$ ", "rationality of distribution layout $\left(S_{01}\right)^{\prime}$, , "convenience of setting the delivery time $\left(S_{04}\right)^{\prime}$ ", "rationality of damaged or lost goods process $\left(S_{07}\right)$ ", "timely notification after goods arrival $\left(S_{12}\right)$ " and "accuracy of logistics information $\left(S_{10}\right)$ ". These six indexes in the middle layer are influenced by the lower layers and influence the service quality indirectly, therefore playing a role in connecting the layers below and above. The reasonable distribution of distribution layout has a significant impact on the convenience of consumers. If the distance is far, it is not convenient for consumers to pick up the package. If it is delivered to the home, the convenience of delivery time has a greater impact on the service quality. Customers expect to receive the packages at a convenient time. Thus, the rationality and timeliness of processing damaged or lost packages may effectively limit the consumers' second source of dissatisfaction. If customers check online that the goods have arrived, but do not receive a call or text message from the delivery staff, it will stimulate anxiety and dissatisfaction of consumption to a certain extent. Moreover, it will also reduce consumers' trust in logistics companies. It can be seen that the six indexes located in the middle layer are mainly based on the customer's perspective. Logistics companies must change from "enterprise - centered" to "customer - centered". Delivering the right goods to the right place at the right time and responding to customers' needs in a timely manner are the driving forces for improving logistics service quality. The indexes located at the first and second layers are "convenience of payment $\left(S_{02}\right)$ ", "convenience of Information query $\left(S_{03}\right)$ ", "convenience of the delivery $\left(S_{05}\right)$ ", "strict regulation of the signing processing $\left(S_{11}\right)$ ", "employees remind customers to open the packages actively $\left(S_{13}\right)$ ", "employees' service attitude $\left(S_{14}\right)$ ", "employees ask what other needs actively $\left(S_{15}\right)$ ", "timely pick-up $\left(S_{16}\right)$ ", "timely goods delivery $\left(S_{17}\right)$ " and "timely goods arrival $\left(S_{18}\right)$ ". These factors focus on three dimensions: service convenience (B1), service caring (B4), and service responsiveness (B5). If the companies perform poorly in relation to these factors, customers will experience obvious dissatisfaction. There is also an element related to the delivery service. The customers' requirements for the timeliness of delivery and timeliness of pick-up are of general importance, and the impact on service quality is on the second layer. Comparing the indexes of the upper and middle layers, it can be found that, in the last mile delivery service, customers pay more attention to the receiving service than the delivery service experience. The correlation between the indexes at the receiving stage is lower than at the delivery service stage. That is to say, the service quality improvement of the receiving link can be addressed from multiple angles at the same time. The improvement of the delivery process quality needs to be carried out sequentially beginning with the most fundamental factors. In summary, the evaluation indexes perceived from the customers' perspective have a significant impact on the service quality of the rural last mile delivery.

The evaluation results of the quality of the rural last mile delivery services of the example enterprises were obtained using the FCE in the previous section, and the impact obtained using the ISM factor stratification results. How can we target the areas of the business that need improvement and prioritize those issues? The following provides a further discussion of Shunfeng Express as an example. The evaluation results of Shunfeng Express are superimposed on the ISM analysis results 
shown in Figure 7 to obtain Figure 8. The service quality evaluation indexes corresponding to the five dimensions are blacked out from deep to shallow. The index of the lowest evaluation result is the darkest. The service response dimension has the lowest evaluation result, and the three evaluation indexes $S_{09}, S_{08}$, and $S_{07}$ of this dimension are located at layer 5 , layer 4 , and layer 3 . It could be speculated that the low scores of these three evaluation indexes are the main reasons for the low service quality evaluation of Shunfeng Express. Therefore, it is necessary to focus on improving these three evaluation indexes first, which are "accuracy of goods arrival $\left(S_{09}\right)$ ", "timely processing of damaged or lost goods $\left(S_{08}\right)$ ", "rationality of damaged or lost goods process $\left(S_{07}\right)$ ". The logistics companies should pay more attention to these three indexes, and make the rural last mile delivery more reliable with the help of corresponding improvement measures. The evaluation result of the service care dimension is second-to-last, and the evaluation indexes $S_{12}, S_{13}, S_{14}$ and $S_{15}$ of the dimension are located at layer 3 , and layer 2 . These indexes are basically determined by the indexes at layer 3 . Therefore, further improvement of layer 3 indexes, which are "timely notification after goods arrival $\left(S_{12}\right)$ ", "convenience of setting the delivery time $\left(S_{04}\right)$ ", "accuracy of logistics information $\left(S_{10}\right)$ ", and "rationality of distribution layout $\left(S_{01}\right)$ " are urgently needed for Shunfeng Express to improve. It is suggested to improve the operation and working ability of employees, which is very important to ensure the accuracy of goods arrival. The following strategies can improve operation efficiency: First, optimization of the distribution route through scientific prediction of distribution demand. Second, through the establishment of a county logistics information platform, to achieve the integration of county logistics resources. Third, the business revenue needs to be increased by providing value-added services such as electrical installation and maintenance.

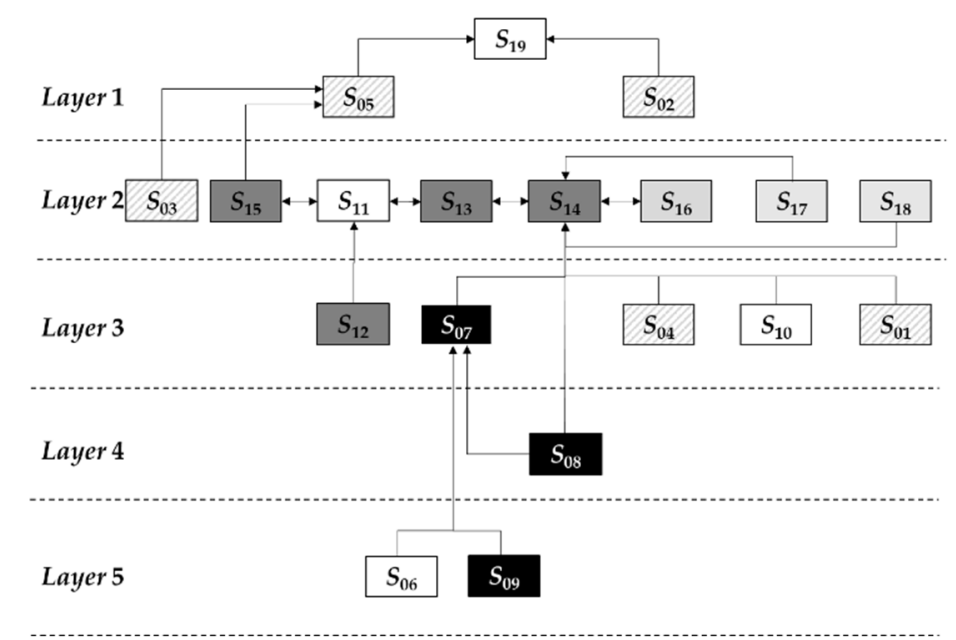

Figure 8. Results of FCE and ISM.

Compared with the traditional logistics service quality evaluation analysis, the exploration of evaluation indexes is helpful to generate new perceptions and improve the system operation quality of rural logistics. This research conducted an in-depth study of service quality evaluation indexes, which were reviewed by two senior managers and professors. These experts were engaged in logistics management for more than 10 years. As the basis of this study, the proposed evaluation indexes may not be exhaustive. However, this service quality evaluation index system contains most indexes that affect system performance, and is recognized by experts.

The stratification results of the evaluation indexes can be obtained by ISM, and provide insight into improving the service quality. The results show that it is necessary to focus on improving certain evaluation indexes first, which are "accuracy of goods arrival" and "timely customer service response". The evaluation indexes perceived from the customers' perspective have a significant impact on service quality of the rural last mile delivery. This finding is basically consistent with the conclusions of previous studies. For example, Jiang found that that four factors, namely, "convenience of returning 
goods", "integrity of goods", "advance reservation of goods pickup", and "delivery costs", were the most basic factors affecting the sustainability of rural logistics [27]. Norizan found that perceived service quality had a significant impact on customer satisfaction [11]. Eduard found that perceived quality was a multidimensional structure, comprising web design, customer service, assurance, and order management; perceived quality had an impact on satisfaction, which affected customer loyalty [10].

In practice, it is necessary to address the issues of improving the service quality in specific cases. By further combining the FCE results of the service quality example, it is possible to propose countermeasures to improve the rural last mile delivery in the example area.

\section{Conclusions}

An integrated methodology of the FCE and ISM was proposed to analyze the service quality evaluation indexes of the rural last mile delivery. First, 18 service quality evaluation indexes in five dimensions were selected, and a questionnaire of last mile delivery service quality in a rural area was used as an example. Second, the FCE was adopted to calculate the service quality evaluation results of the case and the evaluation indexes to be improved were identified. Based on the weight of the evaluation indexes assigned by regression analysis in this case, AEIOU was used to classify the importance of the weight value. Third, the ISM was applied to clarify the hierarchical relationship among various evaluation indexes, and a five-layer hierarchy was obtained. The results show that it is necessary to focus on improving certain evaluation indexes first, which are accuracy of goods arrival and timely customer service response. In the case of Shunfeng Express, the company needs to additionally improve the timeliness and rationality of damaged or lost goods processing. According to the results of the FCE and ISM, some countermeasures and suggestions were put forward to improve the service quality and customers' satisfaction of the rural last mile delivery in the case study area, and enhance the green and sustainable development of rural logistics.

The theoretical implications of this research are as follows. Recent research on the service quality of the rural last mile delivery has been limited to a comprehensive evaluation of the results. Few papers have focused on each of the factors influencing the service quality and their interrelationships. This research comprehensively discusses the relationship between the results of service quality evaluation and the factors influencing it, which can provide more specific improvement measures and suggestions to enhance the service quality. To some extent, this research improves the theoretical approach to the service quality of rural logistics, and provides theoretical decision support for logistics companies to improve the service quality of rural e-commerce logistics.

The practical implications of this study are as follows. Logistics companies can refer to the five-layer hierarchy of evaluation indexes proposed in this paper and focus on improving service quality of the rural last mile delivery sequentially. In particular, it is necessary to focus on improving certain evaluation indexes first, which are "accuracy of goods arrival" and "timely customer service response". In the case of Shunfeng Express, the company needs to additionally improve the timeliness and rationality of damaged or lost goods processing. This study integrates the use of the FCE and ISM, which can identify areas for improvement for specific logistics enterprises, thus helping to prioritize and improve them sequentially, and thereby enhancing customer satisfaction and helping to promote the sustainable development of rural logistics.

The contribution of this paper is shown in the following two points. First, the proposed integrated method can reveal the key evaluation indexes of delivery service quality in specific cases and the areas needing improvement. According to the example of Shunfeng Express, if the service quality of the last mile delivery was merely evaluated, only the evaluation indexes with low scores would be revealed where improvement was needed. However, when proposing countermeasures, the quantification of the importance of each evaluation index is usually ignored, which leads managers to ignore the important evaluation indexes classified to the lowest layer. On the other hand, through the hierarchical results of the evaluation indexes obtained by the ISM, we can only know how to improve the evaluation indexes and the service quality. However, in practice, it is necessary to address the issue 
of improving the service quality of specific cases. Therefore, the integrated results of the FCE and ISM countermeasures and suggestions could be put forward to improve the rural last mile delivery in this case and thus promote sustainable development. The second contribution is the objectivity of the analysis results. The objective weight values are obtained based on the regression analysis method, the evaluation indexes are quantified, and the key indexes are classified, which makes the results objective and provides more reference significance for the countermeasures. Due to the robustness and flexibility of the ISM and FCE, these approaches are widely used in various fields [17-28]. Therefore, the integrated methodology proposed in this paper has certain universality and can be applied to other research environments. However, several shortcomings still remain. For example, the degree of interaction between the two indexes is only expressed by 0 and 1 , which cannot accurately express the actual influence degree. In addition, the application area of this integrated methodology needs to be further tested.

Author Contributions: Conceptualization, X.J. and H.W.; methodology, X.J. and H.W.; software, H.W.; validation, X.J., H.W., and X.G.; formal analysis, X.J.; investigation, X.J. and H.W.; resources, X.G.; data curation, H.W.; writing —Original draft, H.W.; writing—Review and editing, X.J.; visualization, X.J.; project administration, X.G.; funding acquisition, X.G. All authors have read and agreed to the published version of the manuscript.

Funding: This research was funded by Social Science Research Foundation of Jiangsu Province (grant no.18WTA009), and Research subject of China logistics association (grant no.2019CSLKT3-032).

Acknowledgments: We gratefully acknowledge the experts who participated in the study and thank Zhenjun $\mathrm{Zhu}$ (Nanjing Forestry University) for his valuable comments on early drafts.

Conflicts of Interest: The authors declare no conflict of interest.

\section{References}

1. Li, R.L.; Zhang, H.P. China rural logistics market and its characteristics. Chin. Mark. 2008, 6, 138-139.

2. Li, X. An integrated modeling framework for design of logistics networks with expedited shipment services. Transp. Res. Part E Logist. Transp. Rev. 2013, 56, 46-63. [CrossRef]

3. Zhu, Q.; Sarkis, J.; Geng, Y. Green supply chain management in China: Pressures, practices and performance. Int. J. Oper. Prod. Manag. 2005, 25, 449-468. [CrossRef]

4. Parasuraman, A.; Zeithaml, V.; Berry, L. A conceptual model of service quality and its implications for future research. J. Mark. 1985, 49, 41-50. [CrossRef]

5. Parasuraman, A.; Zeithaml, A.; Berry, L. SERVQUAL: A multiple-item scale for measuring consumer perceptions of service quality. J. Retail. 1988, 13, 12-40.

6. Parasuraman, A.; Zeithaml, V.A.; Malhotra, A. E-S-Qual: A multiple-item scale for assessing electronic service quality. J. Serv. Res. 2005, 7, 213-233. [CrossRef]

7. Mentzer, J.T.; Flint, D.J.; Hult, T.M. Logistics service quality as segment-customized process. J. Mark. 2001, 65, 82-104. [CrossRef]

8. Roberts, K.; Varki, S.; Brodie, R. Measuring the quality of relationships in consumer services: An Empirical Study. Eur. J. Mark. 2003, 37, 169-196. [CrossRef]

9. Rafiq, M.; Jaafar, H.S. Measuring customers' perceptions of logistics service quality of 3PL service providers. J. Bus. Logist. 2007, 28, 159-175. [CrossRef]

10. Cristobal, E.; Flavian, C.; Guinaliu, M. Perceived e-service quality (PeSQ): Measurement validation and effects on consumer satisfaction and web site loyalty. Manag. Serv. Q. 2007, 17, 317-340.

11. Norizan Kassim, N.A.A. The effect of perceived service quality dimensions on customer satisfaction, trust, and loyalty in e-commerce settings: A cross cultural analysis. Asia Pac. J. Mark. Logist. 2010, 22, 351-371. [CrossRef]

12. Saura, R.-M.; Palos-Sanchez, P. Are Black Friday Deals Worth It? Mining Twitter Users' Sentiment and Behavior Response. J. Open Innov. Technol. Mark. Complex. 2019, 5, 58. [CrossRef]

13. So, S.; Kim, J.J.; Cheong, K.; Cho, G. Evaluating the service quality of TPL service providers using the analytic hierarchy process. J. Inf. Syst. Technol. Manag. 2006, 3, 261-270.

14. Ghorbanzadeh, O.; Moslem, S.; Blaschke, T.; Duleba, S. Sustainable urban transport planning considering different stakeholder groups by an interval-AHP decision support model. Sustainability 2018, 11,9. [CrossRef] 
15. Chen, K.; Chang, C.; Lai, C. Service quality gaps of business customers in the shipping industry. Trans. Res. Part E Logist. Trans. Rev. 2009, 45, 222-237. [CrossRef]

16. Tansakul, C.H.; Buddhakulsomsiri, J.; Wasusri, T.; Chaiwat, P.; Kritjaroen, T. A gap analysis in service quality of Thai logistics service providers. In Proceedings of the 4th International Conference on Engineering, Project, and Production Management EPPM, Bangkok, Thailand, 23-25 October 2013; pp. 537-550.

17. Li, Y.; Liu, X.; Chen, Y. Selection of logistics center location using Axiomatic Fuzzy Set and TOPSIS methodology in logistics management. Expert Syst. Appl. 2011, 38, 7901-7908. [CrossRef]

18. Kilibarda, M.; Zečevic, S.; Vidovic, M. Measuring the quality of logistic service as an element of the logistics provider offering. Total Qual. Manag. 2012, 23, 1345-1361. [CrossRef]

19. Juga, J.J.; Juntunen, D.B. Grant. Service quality and its relation to satisfaction and loyalty in logistics and outsourcing relationships. Manag. Serv. Qual. Int. J. 2010, 20, 496-510. [CrossRef]

20. Zailani, S.; Jafarzadeh, S.; Iranmanesh, M.; Nikbin, D.; Selim, N. Halal logistics service quality: Conceptual model and empirical evidence. Br. Food J. 2018, 120, 2599-2614. [CrossRef]

21. Warfield, J.N. Toward interpretation of complex structural models. Syst. Manag. Cybern. IEEE Trans. 1974, 4, 405-417. [CrossRef]

22. Thakkar, J.; Deshmukh, S.G.; Gupta, A.D.; Shankar, R. Development of a balanced scorecard: An integrated approach of Interpretive Structural Modeling (ISM) and Analytic Network Process (ANP). Int. J. Oper. Perform. Manag. 2007, 56, 25-59. [CrossRef]

23. Han, Y.; Geng, Z.; Zhu, Q.; Lin, X. Energy consumption hierarchical analysis based on interpretative structural model for ethylene production. Chin. J. Chem. Eng. 2015, 23, 2029-2036. [CrossRef]

24. Thirupathi, R.M.; Vinodh, S. Application of interpretive structural modelling and structural equation modelling for analysis of sustainable manufacturing factors in Indian automotive component sector. Int. J. Prod. Res. 2016, 54, 6661-6682. [CrossRef]

25. Cherrafi, A.; Elfezazi, S.; Garza-Reyes, J.A.; Benhida, K.; Mokhlis, A. Barriers in green lean implementation: A combined systematic literature review and interpretive structural modelling approach. Prod. Plan. Control 2017, 28, 829-842. [CrossRef]

26. Fu, K.; Xia, J.-B.; Zhang, X.-Y.; Shen, J. System structural analysis of communication networks based on DEMATEL-ISM and entropy. J. Cent. South Univ. 2017, 24, 1594-1601. [CrossRef]

27. Jiang, X.; Wang, H.; Guo, X.; Gong, X. Using the FAHP, ISM, and MICMAC Approaches to Study the Sustainability Influencing Factors of the Last Mile Delivery of Rural E-Commerce Logistics. Sustainability 2019, 11, 3937. [CrossRef]

28. Mohanty, M.; Shankar, R. Modelling uncertainty in sustainable integrated logistics using Fuzzy-TISM. Transp. Res. Part D Transp. Environ. 2017, 53, 21. [CrossRef]

29. Tian, Y.Q.; Hua, L.I.; Shang, X.G. Study on affecting factors of risks at workplace based on ISM and AHP. China Saf. Sci. J. 2011, 21, 140-146.

30. Khatwani, G.; Singh, S.P.; Trivedi, A.; Chauhan, A. Fuzzy-TISM: A fuzzy extension of TISM for group decision making. Glob. J. Flex. Syst. Manag. 2015, 16, 97-112. [CrossRef]

31. Duleba, S.; Shimazaki, Y.; Mishina, T. An analysis on the connections of factors in a public transport system by AHP-ISM. Transport 2013, 28, 404-412. [CrossRef]

32. Liu, P.; Li, Q.; Bian, J.; Song, L.; Xiahou, X. Using interpretative structural modeling to identify critical success factors for safety management in subway construction: A China study. Int. J. Environ. Res. Public Health 2018, 15, 1359. [CrossRef] [PubMed]

33. Kannan, G.; Pokharel, S.; Kumar, P.S. A hybrid approach using ISM and fuzzy TOPSIS for the selection of reverse logistics provider. Resour. Conserv. Recycl. 2009, 54, 28-36. [CrossRef]

34. Yang, Z.; Fang, X. Online service quality dimensions and their relationships with satisfaction. Int. J. Serv. Ind. Manag. 2004, 15, 302-326. [CrossRef]

35. Zeithaml, V.A.; Parasuraman, A.; Malhotra, A. A conceptual framework for understanding e-service quality: Implications for future research and managerial practice. In Working Paper, Report No. 00-115; Marketing Science Institute: Cambridge, MA, USA, 2001.

36. Cox, J.; Dale, B.G. Service quality and e-commerce: An exploratory analysis. Manag. Serv. Qual. 2001, 11, 121-131. [CrossRef]

37. Liu, C.; Arnett, K. Exploring the factors associated with web site success in the context of electronic commerce. Inf. Manag. 2000, 38, 23-33. [CrossRef] 
38. Ribbink, D.; van Riel, A.C.R.; Liljander, V.; Streukens, S. Comfort your online customer: Quality, trust, and loyalty on the internet. Manag. Serv. Qual. 2004, 14, 446-456. [CrossRef]

39. Barnes, S.J.; Vidgen, R.T. An integrative approach to the assessment of e-commerce quality. J. Electron. Commer. Res. 2002, 3, 114-127.

40. Loiacono, E.T.; Watson, R.T.; Goodhue, D.L. Webqual: A web site quality instrument. In Working Paper 2000-126-0; University of Georgia: Athens, GA, USA, 2000.

41. Yoo, B.; Donthu, N. Developing a scale to measure the perceived service quality of internet shopping sites (sitequal). Q. J. Electron. Commer. 2001, 2, 31-47.

42. Madu, C.N.; Madu, A.A. Dimensions of e-quality. Int. J. Qual. Reliab. Manag. 2002, 19, 246-258. [CrossRef]

43. Lin, Y.; Lin, L. Research on LAN Performance Evaluation Based on Fuzzy Comprehensive Evaluation Method. J. Phys. Conf. Ser. 2019, 1325, 12047. [CrossRef]

(C) 2020 by the authors. Licensee MDPI, Basel, Switzerland. This article is an open access article distributed under the terms and conditions of the Creative Commons Attribution (CC BY) license (http://creativecommons.org/licenses/by/4.0/). 